\title{
THE CZECH ARMED FORCES CHEMICAL CORPS SPECIALISTS' PROTECTION IN RELATION TO SECURITY THREATS AND THEIR IMPACTS ON SOME TRENDS OF DECONTAMINATION DEVELOPMENT
}

\author{
Pavel OTŘÍSAL*, Zdeněk MELICHAŘÍK** \\ *NBC Defence Institute of the University of Defence, Vyškov, Czech Republic, \\ **Palacký University, Olomouc, Czech Republic, \\ pavel.otrisal@unob.cz zdenek.melicharik@upol.cz
}

\begin{abstract}
Current decontamination mixtures which are established within the Czech Armed Forces are designated for decontamination of all types of surfaces and they are very often prepared by specialists with practically no knowledge related to their destructive properties. The Czech Armed Forces Chemical Corps specialists are challenged to relatively new security threats concerning fight Chemical Warfare Agents and Toxic Industrial Materials in all type of military operations. The aim of the article is to discuss some security threats and some new trends within decontamination and point to the some influences on the Czech Armed Forces Chemical Corps specialists' personnel protection.
\end{abstract}

Keywords: Czech Armed Forces, protection, security threats, Armed Forces, Decontamination, decontamination mixture

\section{Introduction}

The character of the Armed Forces (AF), which must adapt on changing challenges, has to be changed in relation to new tasks that are ahead of the Czech Armed Forces (ACR). Nowadays, the security cannot be compared with the second half of the twentieth century. It is clear, that identification only with the absence of military conflict is not possible in current time. Security is today significantly wider phenomena and in crushing majority clearly civilian, non-military or until recently beyond security perception standing aspects. When building a modern AF is a much greater emphasis on the ability of their interoperability, flexibility, professional performance and technological superiority, which was within the $\mathrm{CHV}$
ACR has frequently discussed.

Generally it is assumed that the risk of interstate conflict is lower than in the past. It can also be said that the more likely adversary of today and the future army will be an army of another state, but rather a terrorist organization, guerrilla or other non-state actors. Nevertheless, the risk of interstate conflict cannot completely ignore, especially in contexts that are currently taking place in Ukraine and Russia. For this reason, alongside the preparation of $\mathrm{AF}$ to resolve asymmetric conflicts should not be underestimated either maintaining sufficient deterrent potential of conventional AF. This fact should not lead to a reduction of preparation only to the most likely, but even the worst scenario for AF. 


\section{Implications threats to the armed forces of the ACR}

Fundamental changes in the design of foreign and national security policy emphasizes generally shared responsibility for peace and security, and the shift from defence of territory to defend the interests, leading to the need for building such AF, which are able to quickly and efficiently even in relatively remote areas of the mother state. Creating rapid reaction forces of the North Atlantic Treaty Organization (hereinafter referred to as "NATO") and the European Union battle groups are not just significant evidence of changes in the concept of building the AF, but also in understanding their deployment in practice as realistically usable foreign and security policy. Ability unprecedentedly narrow and flexible international cooperation is today therefore a necessary condition for successful operation of AF, not only at the level of practical cooperation in the implementation of specific military operations, but especially at the level of policy-making and defence planning.

In this context, and also due to forecasts of its security and economic situation, Czech Republic (CR), as well as many others (especially smaller ones) allied states, is facing a political decision concerning the further development of a wide range of capabilities of its AF. In other words, this means that it is considered to maintain or conversely leaving formally all-armed character army. Her eventual specialization should not be one-sided political step the national team, but should be subject to multilateral consensus within NATO and balanced reciprocal guarantee provision inhibited abilities. Specialization in addition not only focus on the development of specific military capabilities due to their lower economic performance or maintaining momentary technological advantage, but also envisages a quantitative expansion of their use in favour of the other allies at a scale much larger than was hitherto needed at national level [1,2].
Nowadays, it appears that together with personnel, technological and financial demands of extraterritorial activities of modern AF is expanding variety of tasks which traditionally incumbent to other security forces in the past or they have not given sufficient attention. A typical example of such tasks may be deployment of the military force in the tasks of surveillance civilian objects ammunitions depots in Vrbětice (Czech Republic).

For the current AF is usually not a problem quickly and without unnecessary loss of military stalemate, but in the subsequent post-conflict phase are often forced to deal with a problematic result of those tasks that are not prepared or they do not have traditional experience. This is essentially a police action, representation functions of civilian administrative authorities and civilian crisis management structures, infrastructure renewal conflict affected areas, support for the establishment or strengthening of a new polity, creating a positive media image of his tenure, nonmilitary response to Chemical, Biological, Radiological and Nuclear (CBRN) situation etc. There is a growing need for cooperation with external civilian crisis management structures or even creating their own direct capabilities, including civilian elements. Even on these tasks must be prepared army, trained and educated, even if it is a question in the debate, how much would that activity should be a priority when it comes to issues related to the protection of the civilian population. What must not be subject to debate, the issues of protection of military forces and resources against the consequences of contamination of weapons of mass destruction (WMD) and for toxic industrial materials releases of hazardous substances in military operations. Leaving aside the fact that these tasks are primarily maintained at the level of combined arms, so its crucial role to play and chemical corps of the ACR especially at a time when it is necessary to use specialized forces and means and to use the knowledge of its 
specialists.

In this context, it might be worth considering returning to the definition of the mission of the AF, its closer definition and determination of its distinct limits. The armed forces play a role of extreme violent means of defence and the defence of vital interests. From this perspective, it is paradoxically the biggest success of foreign and national security policy is zero need for their deployment. The armed forces are not intended to substitute functions of other state security forces, especially in the remediation of non-military threats, not allsolved means of resolving any safety problem. Expanding competencies of $\mathrm{AF}$, also led by a political need for easier defence relatively large economic costs for maintenance and development of the army, it is not possible indefinitely. The primary task of the AF is primarily to defend and deter and these missions would lead the state and ordinary citizens should always have in mind in particular.

\subsection{Durability and protection forces and their impact on $\mathbf{A F}$}

Resistance and force protection to minimize the effects of any adverse or the hostile actions are important to minimize loss of strength and live material and preserve combat power of AF. Effective protection of deployed forces and means and their durability is based on early warnings AF about upcoming and carried out air strikes adversary, land, naval and missile means conventional and chemical, biological, or even nuclear munitions. The armed forces protect with the implementation of active measures, which primarily means the destruction means adversary or passive measures, such as sheltering manpower and material, building protective structures, diversion over a larger area, camouflage and deception. An important capability to assist and protect the resistance forces is high mobility, to avoid the blows opponent, change rooms and deployment activities quickly dissipate and re-focus and material. This will help with the construction and defence and communications infrastructure. An important condition for effective resistance and force protection will remain effective air defence preventing lead opponent of targeted strikes on AF in all kinds of activities [3].

In practice this means for the CRAF in particular to:

- maintain a leadership role in skills development, in which the $\mathrm{CR}$ and its AF occupy a leading position (CBRN protection, passive reconnaissance systems, medical support, etc.);

- contribute to deeper integration of allied air defence system and thus contribute to a better awareness of specialists of the chemical corps about potential threats arising from the use of WMD;

- reduce the share of human operators in the use of weapons and other systems by introducing new reconnaissance and decontamination equipment;

- develop ability longer autonomous action of individuals on the battlefield with the knowledge to ensure its adequate protection;

- develop mobility including the ability to assault and efficient movement especially in built-up a contaminated area;

- further deep survival skills, encompassing a safety equipment (equipment and accessories) soldier, combat identification, protective camouflage and protection against WMD. In this context, it is not possible to forget the gear specialists chemical ACR, that must be the long-term effects linked to resist the action of decontamination mixture in the tasks of combat support forces in implementing the measures falling within the CBRN protection, as well as in the category of chemical support forces in operations.

3. Challenges in decontamination and protection against the effect of decontamination specialists mixtures

The year 2013 became crucial for the determination of changes in the approach to 
decontamination in the Army as a whole. There was also unleashed a very useful discussion, which aimed to describe the current state in support of decontamination of technical means and mixtures and set new trends that its effectiveness should be significantly promoted. The approaches which have been proposed as the fundamental challenges were summarized as follows: [4]

- to rationalize the system of decontamination mixtures in ACR - to leave mixtures ODS-5 and OP-3, to establish mixture of EDS;

- to solve problems of decontamination of air vehicles with the aim of develop corresponding decontamination mixtures ant technical devices for their decontamination;

- to complete the development of compounds for the decontamination of internal surfaces and sensitive materials, including the method of application and compositions for individual protection;

- to carry out research and development in the field of detection and disposal of process water after decontamination;

- to deal with the issue of technical means for partial deactivation of military vehicles and material;

- to develop study to problems of light decontamination teams;

- to solve maintaining of training of decontamination attendants by training contaminants and decontamination agents, which will enable the safe and environmentally friendly training;

- to begin solving problems of checking of thoroughness of decontamination;

- to solve problems of setting standards area decontamination mixtures consumption depending on the temperature, the temperature range for about 10 to $15^{\circ} \mathrm{C}$;

- to initiate development of a solution means for immediate decontamination device intended for equipment;

- to initiate negotiations with the authorities on the issue of logistics to problems of decontamination kits, strum and laundry;

- to implement control application (spraying) specified quantity of the mixture using a spray streamlines.

As the principle we consider such as conclusions of the seminar which was held in 2013 at the NBC Defence Institute of the University of Defence whose application would maximally decrease the danger of decontamination mixtures and their components during a contact of barrier materials formed with butyl-rubber with them.

Even though these findings were not exactly mentioned neither published with their study can be traced some trends that make this vision more or less support. The most important of them consider the following:

- to implement rationalization of decontamination mixtures and their components in order to eliminate those organic substances which have a destructive effect on the underlying barrier material, which is used as starting material for the production of structural chemical protective clothing OPCH-05. As an example can be mentioned the decontamination mixture number 1 whose base is created with dichloroamine in dichloroethane in the ration of $1: 9$. Destructive effects of this decontamination mixture have been sufficiently demonstrated and clearly support arguments for its exclusion from the ACR. In the same way, it is possible to talk about decontamination hypochlorite mixtures, which include diesel fuel. It is essentially a purely nonpolar, which is the basic problem of negative affecting in contact with a nonpolar butyl rubber;

- when dealing with decontamination of aircraft technology in order to develop appropriate decontamination mixture and technical resources for their decontamination to focus on research and development of such mixtures, whose influence on the barrier materials 
will be minimal. It will be appreciated that semi-automatic or mechanical application of decontamination mixtures may be associated with their run-off and subsequent uncontrolled continuous contact with polymeric materials that form a barrier between the environment and the user's body surface;

- to complete development mixtures for decontamination if inner surfaces and sensitive materials including their application and mixtures for devices of individual protective equipment. During this effort it is necessary to consider about such as aspects of application on individual protective equipment which will have influence on barrier materials which are used by chemical corps specialists. The materials used are vastly different, and therefore their effects must be studied and taken into account separately;

- to carry out a study on the issue of light decontamination teams. This study not only focus on implementation issues decontamination operations themselves as such, but also maintaining of force protection for their rest and be able to work for as long as required by the relevant standards. It is evident that if the specialist need to perform the task of operating throughout one or several successive operating intermittently successive shifts, so its isolative clothing must be perfectly resistant or designed so as to prevent its destruction or distortion effects associated with intense swelling e.g. polymer blends and the like

- in addressing issues of maintaining of training of decontamination attendants by training with contaminants and decontamination agents, which will enable the safe and environmentally friendly training, highlighting the fact that in real terms chemical protective clothing might not provide a level of protection that is declared using alternatives. Already there is sufficient awareness of the fact that alternative test substance, or otherwise also simulates their chemical nature are usually quite different and not replace the experience that would have been obtained when training with real decontamination mixtures or chemical warfare agents. These experiences should be regarded as irreplaceable;

- to start solving problems of the check of completeness of decontamination. Thus, from the information could, at its outset directed more to check the effectiveness of decontamination as such, thus the combined arms, which would tend to check the effectiveness of chemical decontamination kits combined arms. It must be forgotten on performing decontamination such as individual protective equipment used by specialists. Even their individual protective equipment can be contaminated after finishing a operation shift or after finishing operational task.

- when dealing with the establishment of standards of area consumption decontamination work blends with the fact of existence having a semiautomatic mechanical method of preparation of decontamination mixtures in which the personal assistance specialists of the chemical corps ACR indispensable and irreplaceable;

- to implement control application (spraying) specified quantity of the mixture by using spray streamlines. During this inspection could be considered aspects such as the sensor control of contamination of isolative individual protective equipment. Information about the contact of isolative means of protecting of the body surface with a decontamination mixture of or its components could lead to the adoption of operational decisions to reduce the time of executing operational tasks in terms of regulation lengths operational shifts. 


\section{References}

[1] KAZANSKÝ, Rastislav a i. 2011. The aspects of contemporary problems of weapons of mass destruction proliferation. In Bezpeka žitija i dijal’nosti l’judini - osvita, nauka, praktika "BŽDL 2011" : zbornik naukovych prac 10-oj mižnarodnoj naukovometodičeskoj konferenciji. Kyjev : Nacional'nyjaviacijnyj universitet, Institut ekologičnoj bezpeki, 2011, s. 11-15.

[2] KAZANSKÝ, R., ADAŠKOVÁ, D. 2010. Selected aspects to the access to the conficts classification (In Slovak). In Bezpečnostné fórum 2010. Banská Bystrica: Faculty of Political Science and International Relations University of Matej Bel, 2010. ISBN 978-808083-980-2, p. 53-59.

[3] ZABADAL, Miroslav. CBRN Protection in the System of Force Protection (in Czech). Brno : Institute of operational and strategic studies, 2005, textbook S - 3623, $124 \mathrm{p}$.

[4] ŽUJA, Petr; SKALIČAN, Zdeněk. Decontamination in the Czech Armed Forces (in Czech). LISTY UNIVERZITY OBRANY, 2013, item 9, No 4, p. 8. MK ČR E 15403. 